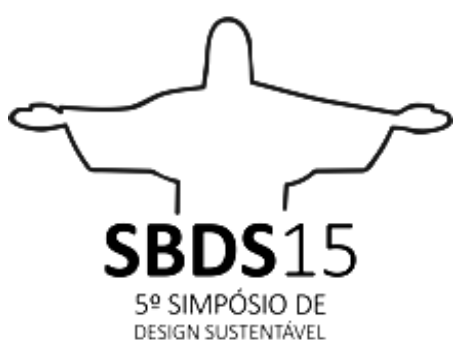

\title{
O USO DA LÃ COMO MATÉRIA-PRIMA PARA O DESENVOLVIMENTO DO DESIGN SUSTENTÁVEL
}

Érica Arrué Dias

Mestranda PPG em Design

Centro Universitário Ritter dos Reis

e.arruedias@gmail.com

Anne Anicet

Doutora em Design

Centro Universitário Ritter dos Reis

anne_anicet@uniritter.edu.br

\begin{abstract}
Resumo: O presente trabalho versa sobre a relação da lã, importante matéria-prima do vestuário, com as diretrizes propostas por Carlo Vezzoli para o desenvolvimento de projetos sustentáveis. Para isso, em um primeiro momento, através de um referencial bibliográfico, discorremos sobre a lã, sua história e suas qualidades como matéria-prima. Em um segundo ato são tratadas questões sobre a usabilidade da lã nos pilares da sustentabilidade ambiental, social e econômica, além da análise de uso enquanto matéria-prima para o desenvolvimento de produtos sustentáveis.
\end{abstract}

Palavras-chave: Design, sustentabilidade, lã, matéria-prima.

\section{Introdução}

Sustentável, do latim "sustentare", significa suportar, sustentar, conservar, manter. Logo a expressão sustentável se refere a tudo aquilo que pode ser sustentado, que é passível de sustentação e de conservação (BARCELOS, 2012). Esse conceito de sustentabilidade talvez seja a maior crítica e o maior desafio que a moda tem recebido atualmente. É chegado o momento em que precisamos pensar nas repercussões de todas as atividades relacionadas ao setor. Para o presente estudo buscou-se conhecer uma matéria-prima muito usada no Rio Grande do Sul (Estado localizado no Sul do Brasil) com inúmeras qualidades e que também é muito usada na indústria da moda, a lã.

Para tal, foram analisadas suas qualidades como fibra e aptidões para o desenvolvimento de projetos de design sustentável, através da fundamentação dos pilares da sustentabilidade, propostos por Carlo Vezzoli em seu livro Design de Sistemas para a Sustentabilidade, publicado em 2010. 
Os objetivos deste estudo é perceber se há relação do presente material têxtil com as diretrizes propostas pelo autor e sob quais aspectos pode ser considerada uma matéria-prima sustentável.

Visando uma boa compreensão do presente relato, iniciaremos o trabalho introduzindo um breve histórico sobre a fibra assim como sua importância econômica e cultural para a região.

\section{Sobre a lã}

\section{A HISTÓRIA DA LÃ}

A lã é a mais antiga fibra natural usada na história, tendo indícios de que na Idade da Pedra o homem usava o pêlo de carneiro como proteção e agasalho. $\mathrm{Na}$ Turquia, foram encontrados vestígios de lã, tecida, 7 mil anos antes da nossa existência, assim como no Oriente Médio onde encontrou-se fragmentos de lã do Período Neolítico (10.000 a.C à 4.000 a.C). Na América do Sul, nos Andes, os ameríndios, na época pré-colombiana, teciam a lã de vicunha também conhecida por sua finura (PEZZOLO 2007).

Conforme Pezzolo (2007), foi em 1556 que chegaram os primeiros ovinos no Brasil, trazidos pelos colonizadores portugueses. No Rio Grande do Sul, a primeira estatística oficial de ovinos foi realizada no ano de 1797 e somava 17.475 animais (SANTOS, 1968 apud SANTOS, AZAMBUJA \& VIDOR, 2009). Há aproximadamente dois séculos depois, na década de 70, o Estado chegou a quantidade de cerca de 12 milhões de animais, devido a importância econômica da lã registrada na época, quando atingiu o valor de $\bigcup \$ \$ 3,83 / \mathrm{kg}$ durante a safra de 1988/1989. Nesse mesmo período o volume de produção de lã no Rio grande do Sul, chegava a 36 mil toneladas por ano (FIGUEIRÓ, 1975 apud SANTOS, AZAMBUJA \& VIDOR, 2009).

Porém, segundo Ávila et al (2013), no final da década de 80 ocorreu a pior crise mundial do setor, que se estendeu durante toda a década de 90. De acordo com o autor essa crise se deu em decorrência do grande estoque de lã da Austrália, onde ainda se encontra a maior produção mundial, que com o objetivo de regular os valores monetários da matéria criou um mecanismo, baseado em compra e venda 
de grandes quantidades do produto. Contudo, os preços mais elevados, fizeram com que os consumidores optassem pelo consumo de fibras sintéticas e algodão.

A crise mundial afetou os rebanhos gaúchos, causando a diminuição de cerca de metade da produção de ovinos que se tinha na década de 70 , chegando ao número de 5,6 milhões de animais, o que resultou na queda do preço da fibra, que chegou a U\$ $\$ 1,52 / \mathrm{kg}$ (ÁVILA et al, 2013).

Entretanto Dias (2013) defende que, depois de muitos anos, hoje a ovinocultura voltou a crescer no Estado, a carne vive momento de alta valorização e a lã de recuperação dos seus preços. A região atinge hoje o número de 4 milhões de animais e é responsável por mais de $90 \%$ da produção de lã do país.

Para o autor, "a ovinocultura, na maioria dos casos, mais do que uma atividade econômica, é uma paixão enraizada na cultura de milhares de produtores que se dedicam no dia-a-dia a trabalhar com ovelhas em nosso Estado" (DIAS, 2013, p 9).

\section{A LÃ COMO MATÉRIA- PRIMA}

Mesmo após a crise, a lã até hoje é valorizada devido as suas diversas qualidades. Entre todas as fibras é a mais hidroscópica, ou seja, ela tem uma grande capacidade de absorver umidade da atmosfera, sem ficar molhada e absorve também a transpiração, contribuindo para baixar a temperatura do corpo nos dias mais quentes. Isso confere a lã a propriedade de isolante térmica, tanto do frio quanto do calor. Outra qualidade importante é a capacidade da fibra de ser não inflamável, quando em contato com o fogo, extingue a combustão. Além é claro, quando limpa e tratada é macia ao toque, tem um caimento natural e é de grande durabilidade (AQUISTAPASSE, 2001; PEZZOLO, 2009).

Conforme Bernhard (2013), a lã é uma fibra resistente, forte, porém flexível, e elástica, fácil de cuidar e manter, não amassa e não perde sua forma. Tem propriedades antialérgicas, terapêuticas, protege dos raios UV e é considerada uma matéria-prima sustentável.

Na moda brasileira, o uso da lã não pode ser comparada, em termos de uso, ao de outras fibras naturais, como o algodão por exemplo, é provável que isso 
ocorra devido ao clima tropical do país e a percepção de que a lã é um tecido ideal apenas para o inverno.

Sabendo dessa dificuldade de aceitação do mercado brasileiro, fiações e tecelagens investem atualmente, na produção de fios cada vez mais finos e de tecidos leves e maleáveis. Os métodos de produção de roupas de lã, no Rio Grande do Sul, continuam com o viés artesanal e valorizam técnicas clássicas como o tricô e o crochê, a tecelagem, tanto manual quanto industrial, e o feltro.

Fio de lã super fino, tingido com carqueja.

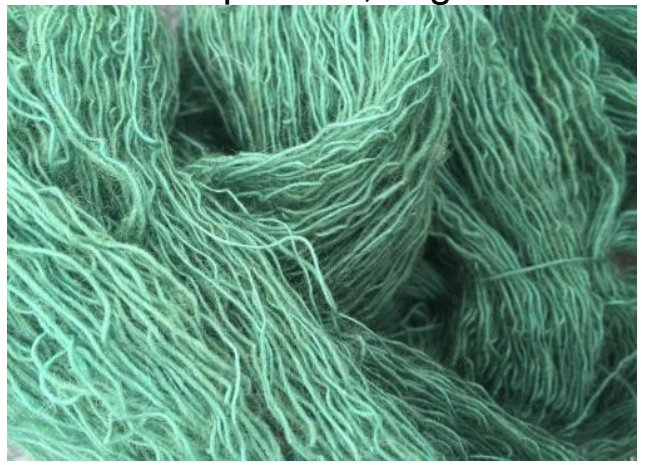

Fonte: a autora (2015).

\section{Moda, Lã e Sustentabilidade}

Segundo Fletcher e Grose (2011), a indústria têxtil é considerada uma das principais vilãs do setor, e está associada a todo tipo de impacto sustentável. Uma das principais acusações está relacionada ao não uso de recursos renováveis, à geração de resíduos químicos e à poluição e desperdício da água.

Para Vezzoli (2010) produtos e marcas sustentáveis devem estar consolidados sob três principais pilares: Sustentabilidade ambiental, social, econômica. No nível ambiental, se encaixam todas as prioridades referentes ao cuidado com o meio ambiente, como escolha de materiais adequados que minimizem o risco de emissões tóxicas e danosas, que de preferência sejam fontes biodegradáveis e renováveis. Sobre a sustentabilidade social, o autor defende que a produção deve levar em consideração as condições de trabalho, melhorar a coesão social e valorizar a mão de obra local. E por fim, as prioridades da sustentabilidade econômica, onde deve-se pensar no valor agregado a cada produto, no efeito macroeconômico de sua produção e no posicionamento de mercado da marca. A 
seguir analisaremos as perspectivas da lã em relação aos pilares da sustentabilidade, sugeridas pelo autor.

\section{LÃ E SUSTENTABILIDADE AMBIENTAL}

Conforme Vezzoli (2010), os danos ambientais são resultados de uma troca de substâncias entre o sistema de produção e a natureza. Essas trocas ocorrem em dois sentidos, como entrada (input) ou como saída (output). O efeito ambiental causado na entrada é derivado da extração de substâncias da natureza, enquanto na saída é fruto da emissão de substâncias na natureza.

Vezzoli (2010) indica o uso de recursos renováveis para que os impactos causados nas trocas de entrada, por exemplo, não sejam tão danosos e assim também preserve os recursos naturais que ainda nos restam. Assim, conforme Bernhard (2013), a lã pode ser considerada uma matéria-prima ambientalmente sustentável, dado que diferente de outras matérias, ela é extraída de forma natural, já que é necessário esquilar os animais, no mínimo, uma vez ao ano, por questões de saúde e bem-estar dos mesmos.

Já para minimizar os efeitos das trocas de saída, Vezzoli (2010) defende que o sistema produtivo deve prevenir a poluição e buscar reduzir ao máximo as emissões de substâncias danosas ao meio ambiente e assim aumentar a biocompatibilidade. Portanto, de acordo com Fletcher e Grose (2011), outro quesito ambiental é no controle do desperdício de água e emissão de efluentes tóxicos e sob este aspecto a lã pode ser inserida. Isso porque esta fibra permite a absorção de tingimentos naturais, com pigmentos extraídos de ervas, folhas e raízes, possibilitando um maior controle dos gastos de água, fácil tratamento da mesma, e emissão de efluentes naturais, rapidamente absorvidos pelo ambiente, sem danos a natureza.

Essas técnicas de tingimentos artesanais são milenares, porém os corantes de origem natural foram utilizados somente até meados do século XIX. Nesse período, passaram a ser substituídos por corantes orgânicos artificiais, originados por composições químicas, em sua maioria derivados do alcatrão e do petróleo, que produzem um beneficiamento mais eficaz e uma coloração mais uniforme.(Aquistapasse, 2001, Chantaignier, 2006) 
Porém, o uso de corantes químicos vêem causando preocupações nos setores ambientais, segundo Fletcher e Grose (2011), dados mostram que o processo de tingimento usa, em torno, de 387 bilhões de litros de água por ano. Outro fator que preocupa, é a poluição causada pelo efluente gerado após o processo químico, já que $90 \%$ desse corante é eliminado, em água, após cumprir o beneficiamento.

Segundo Dias (informação verbal, 2014) é devido a essas preocupações que o uso dos corante naturais e as formas artesanais de tingimento estão sendo resgatadas pelas cooperativas e artesãs do estado do Rio Grande do Sul.

Porém é importante ressaltar, que o uso de pigmentos vegetais também consiste em uma troca de entrada e deve-se levar em consideração sua preservação e renovação.

\section{LÃ, ARTESANATO E SUSTENTABILIDADE SOCIAL E ÉTICA}

Para Vezzoli (2010) não podemos falar de sustentabilidade sócio-ética sem esclarecer o conceito chamado de princípio da equidade. Segundo o autor esse princípio busca uma distribuição justa de recursos, espaço, acesso à mesma disponibilidade de recursos naturais e ao mesmo nível de satisfação que pode ser obtido através destes.

Além desta distribuição justa, quando o princípio da equidade se relaciona com questões sócio-éticas o conceito se amplia e abrange questões como os princípios e regras da democracia, direito a liberdade, direitos humanos, direito a paz e a segurança, redução da pobreza e injustiça, direito ao acesso a informação, capacitação e emprego, além de buscar o respeito à diversidade cultural, identidade e biodiversidade (ONU, 2002 apud VEZZOLI, 2010).

Portanto, para um desenvolvimento sustentável é importante buscar a melhoria de qualidade de vida e promover igualdade de oportunidade para todos envolvidos no processo. Este é outro fator em que a lã como matéria-prima pode ser vista sob o aspecto sustentável. Hoje no Rio Grande do Sul existem dezenas de cooperativas dedicadas aos trabalhos de lanifício, como também diversas artesãs que vivem de fazer tricô e crochê com a lã gaúcha. A imagem abaixo mostra o 
estilista Ronaldo Fraga compartilhando seu conhecimento com as artesãs da Cooperativa Lã Pura da cidade de São Borja - Rio Grande do Sul.

Ronaldo Fraga em oficina com a cooperativa Lã Pura

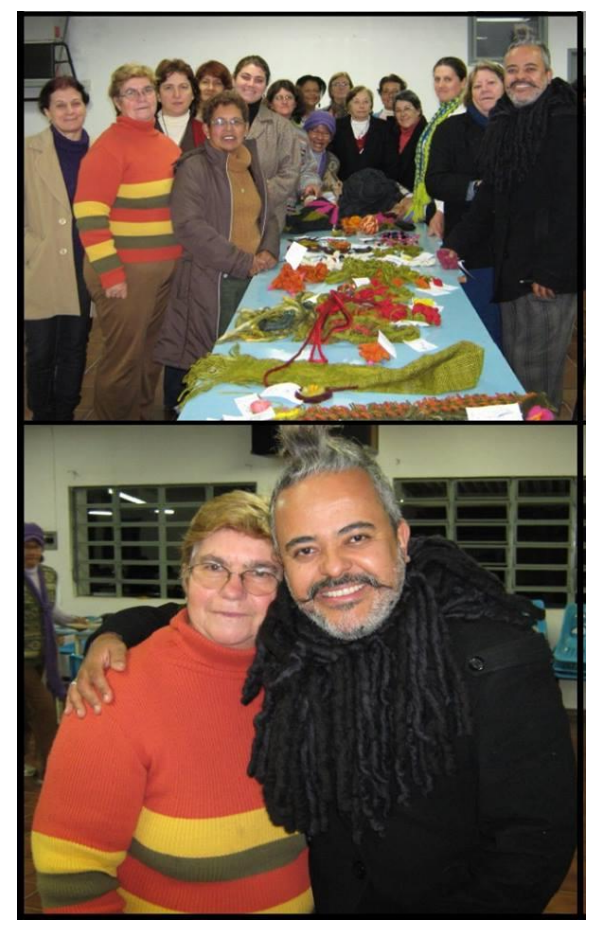

Fonte: Página da Lã Pura Cooperativa no Facebook.

Além disso, a EMATER/RS - Associação Rio-Grandense de Empreendimentos de Assistência Técnica e Extensão Rural, promove políticas públicas que visam a inclusão social e produtiva de jovens e idosos na cadeia produtiva de desenvolvimento rural. Um dos projetos da Associação traz 0 artesanato rural como fonte de complemento da atividade familiar, assim como uma interação entre as comunidades tradicionais e o turismo rural.

"O artesanato tem como objetivo estimular e promover o desenvolvimento de capacidades artísticas e resgates culturais, proporcionando ao artesão a qualificação profissional, o desenvolvimento de técnicas de aproveitamento progressivo das matérias-primas presentes no meio rural, associadas à busca de mercado para a comercialização de seus produtos e inserção da atividade nas políticas públicas, assim como gerar emprego e renda de forma complementar ao orçamento familiar rural, observada a adequação e a legalidade comercial" (EMATER/RS, 2015). 
Assim, visando o desenvolvimento sustentável pode-se relacionar a matériaprima em questão, produzida em grande quantidade e alta qualidade no Estado, com os trabalhadores locais e rurais, para que complementem suas atividades, aumentem sua fonte de renda, promovendo coesão social e melhoria da qualidade de vida, além de desenvolver projetos de cunho cultural e afetivo.

Uma das coisas boas do artesanato é que as artesãs muitas vezes podem desenvolver seus trabalhos em casa, sem que o trabalho as desloque dos seus ambientes familiares. Muitas delas têm a responsabilidade de cuidarem das crianças e idosos de suas famílias e de pessoas próximas e, para tal, só conseguem ganhar alguma renda na medida que desenvolvem estas atividades em casa.

\section{LÃ E SUSTENTABILIDADE ECONÔMICA}

Segundo Vezzoli (2010), precisamos pensar nos valores atribuídos aos recursos naturais, bem como os custos indiretos de produção. Um fator economicamente importante de analisar quando nos referimos à produtos de lã é a otimização do ciclo de vida produtivo, isso porque a lã é uma matéria-prima que permite sua inteira reciclagem e reaproveitamento. Esses produtos quando descartados podem ser desmanchados e gerar um novo produto, com a mesma fibra, sem que essa precise passar por processos de adaptação. Essa reciclagem de matéria-prima possibilita a redução das entradas de recursos naturais, bem como as saídas de substâncias oriundas do processo de beneficiamento.

Outra vantagem econômica, e que também é sócio-ética, do uso da lã e artesanato conforme abordado anteriormente, é a possibilidade dos artesãos trabalharem em sua residência, dispensando a necessidade de infraestrutura de trabalho, diminuindo o uso de transporte, energia e suporte de pessoal. Isso também torna os trabalhadores economicamente ativos e independentes.

Assim como um fator ambiental, o tingimento artesanal encaixa a lã nos requisitos econômicos, pois, como já citado, esse método propicia o controle do uso, desperdício e tratamento da água utilizada no processo de beneficiamento. Segundo Vezzoli (2010) evitar o impacto ambiental durante o desenvolvimento de um determinado produto também faz parte das diretrizes economicamente eficientes. 


\section{Considerações Finais}

Segundo Manzini e Vezzoli (2011), todo esse método de produção sustentável só pode ser válido e consolidado se existir um cenário sociocultural favorável, ou seja, uma necessidade e constante busca, por parte da sociedade, de melhorar o grau de bem estar e sua qualidade de vida. Os autores defendem que para isso:

\footnotetext{
"é preciso que sejam transformados os juízos de valores e os critérios de qualidade que interpretam a ideia de bem-estar. Para delinear o nosso cenário neste terreno, é, pois, necessário imaginar que haja uma profunda mudança na cultura até aqui dominante. (MANZINI E VEZZOLI, 2011,p 55)
}

Conforme Lilyan Berlim (2012) o tema da sustentabilidade na contemporaneidade nos obriga a repensar as atitudes e decisões que tomamos diariamente. Segundo a autora, "sustentabilidade não está apenas relacionada a ações de filantropia, gestão de resíduos ou plantio de árvores, mas a uma reorganização da visão de mundo de cada cidadão".

Estamos em um tempo em que precisamos questionar e refletir sobre o que consumimos, como consumimos, quais as consequências deste consumo para o desenvolvimento humano e o importante papel do designer dentro deste contexto de sustentabilidade ampla.

Ainda sobre a esfera do design sustentável, as pesquisas do setor de moda e produção têxtil recentemente passaram a abranger as questões sociais, culturais, econômicas e políticas, e não apenas o aspecto ambiental de produção de bens e serviços. (BERLIM, 2012)

Portanto, após refletir sobre a inserção da lã como matéria-prima nas diretrizes e requisitos sustentáveis propostos por Carlo Vezzoli, em seu livro Design de Sistemas para a Sustentabilidade (2010), é possível analisar que a fibra pode ser considerada uma matéria têxtil sustentável, pois ela habita ambos os três parâmetros de produção consciente recomendados pelo autor.

Assim, concluímos que a lã é uma boa alternativa para o desenvolvimento de produtos considerados sustentáveis e deve ser usada por designers e profissionais 
que estejam em busca de opções favoráveis para o meio ambiente, para as pessoas participantes e para a sociedade em geral.

\section{Referências}

AQUISTAPASSE, Lusa Rosângela Lopes. Cultura Material: A Estamparia Têxtil Como Fator de Inovação de Tecidos de Lã. Santa Maria: 2001.

ÁVILA, Viviane et. All. O Retorno da Ovinocultura ao Cenário Produtivo do Rio Grande do Sul. Revista Eletrônica em Gestão, Educação e Tecnologia Ambiental, UFSM, Santa Maria, Volume 11, páginas 2419 - 2426, Junho de 2013. Disponível em: http://cascavel.ufsm.br/revistas/ojs2.2.2/index.php/reget/article/view/8801/pdf Acessado em 10 de Julho de 2015.

BARCELOS, Silvia Mara Bortoloto Damasceno. Indicadores de sustentabilidade em indústrias de vestuário no APL de Maringá/Cianorte - PR.

BERNHARD, Eduardo Amato. Produção Sustentável e Alternativas para o Mercado de Lã. In: CONGRESSO LATINOAMERICANO DE ESPECIALISTAS EN PEQUENOS RUMIANTES Y COMÉLIDOS SUDAMERICANOS. Páginas $8-16$, 2013.Disponível em: http://www.caprilvirtual.com.br/Artigos/CongressoLatinoamericanoPequenosRuminan tes2013/palestras/0000011186-PALESTRA2Bernhard.pdf Acessado em: 10 de Julho de 2015

CHATAIGNIER, Gilda. Fio a Fio: Tecidos, Moda e Linguagem. São Paulo: Estação das Letras e Cores, 2006.

DIAS, José et. All. Guia Prático do Ovinocultor. Porto Alegre: Secretária da Agricultura, Pecuária e Agronegócio, 2013.

EMATER/RS. Artesanato Rural. Área Técnica. Disponível em: http://www.emater.tche.br/site/area-tecnica/agregacao-de-valor/artesanatorural.php\#.Vd4T_0tH8cc Acessado em: 10 de Julho de 2015.

FLETCHER, Kate; GROSE, Lynda. Moda e Sustentabilidade: Design para Mudança. São Paulo: Editora Senac, 2011.

BERLIM, Lilyan. Moda e Sustentabilidade: Uma reflexão necessária. São Paulo: Estação das Letras e Cores, 2012. 
MANZINI, Ezio; VEZZOLI, Carlo. O Desenvolvimento de Produtos Sustentáveis: Os Requisitos Ambientais dos Produtos Industriais. São Paulo: Editora da Universidade de São Paulo, 2011.

PEZZOLO, Dinah Bueno. Tecidos: História, Tramas, Tipos e Usos. São Paulo: Editora Senac, 2007.

SANTOS, Diego Viali; AZAMBUJA, Roberto Moreira; VIDOR, Ana Carla Martins. Dados Populacionais do Rebanho Ovino Gaúcho. A Hora Veterinária, volume 185, páginas 28-31, 2012.

VEZZOLI, Carlo. Design de Sistemas para a Sustentabilidade. Teoria, Métodos e Ferramentas para o Design Sustentável de "Sistemas de Satisfação". Salvador: Edufba, 2010. 